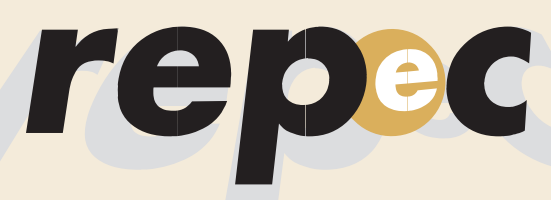

REPeC, Brasília, v.8, n.1, art. 2, p. 22-38, jan./mar. 2014 Disponível online em www.repec.org.br
Revista de Educação e Pesquisa em Contabilidade

Journal of Education and Research in Accounting

Revista de Educación e Investigación en Contabilidad

Periódico Trimestral, digital e gratuito publicado pela Academia Brasileira de Ciências Contábeis

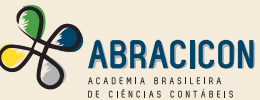

\title{
Adoção de IFRS e gerenciamento de resultado nas empresas brasileiras de capital aberto
}

\section{Resumo}

O Brasil adotou em 2007 as normas internacionais de contabilidade - International Financial Reporting Standards (IFRS). Pesquisas realizadas com empresas de capital aberto em vários países do mundo indicam que essa nova norma tende a melhorar a qualidade da informação e deixá-la mais comparável e transparente. Diante disso, o estudo tem como objetivo verificar se houve mudança nos níveis de gerenciamento de resultados após 2010 e se foi em função da adoção completa de IFRS pelas companhias brasileiras de capital aberto (com exceção das instituições financeiras). Os dados foram extraídos das demonstrações contábeis trimestrais dos bancos de dados do Economática e da Comissão de Valores Mobiliários referentes ao período de 2006 a 2011. Para alcançar o objetivo da pesquisa, foram feitos dois testes. O primeiro mostrou que os accruals discricionários, calculados por meio do Modelo de Jones Modificado, tiveram média menor após 2010. Em seguida, foi elaborada a análise de regressão com dados dispostos em painel com correção de Newey-West. Os resultados não confirmaram a hipótese de que a adoção de IFRS afetou o nível de gerenciamento de resultados no período analisado, mas mostraram que o tamanho e o endividamento explicam significativamente os accruals discricionários, independentemente da adoção de IFRS. Os resultados sugerem que empresas maiores e com maior proporção de capital próprio tendem a produzir relatórios com melhor qualidade, independentemente da adoção de IFRS.

Palavras-chave: Gerenciamento de resultados. Accruals Discricionários. Adoção de IFRS.

\section{Roberto Midoguti Joia}

Mestre em Controladoria e Contabilidade pela FEARP/USP, assistente A no Banco do Brasil e professor da UNIP. Contato: Rua nove de julho, 842, Centro, Guariba, SP, Brasil, CEP: 14840-000.

E-mail: robertomjoia@yahoo.com.br

\section{Sílvio Hiroshi Nakao}

Livre-Docente em Contabilidade pela FEARP/USP e professor da Universidade de São Paulo em Ribeirão Preto. Contato: Av. Bandeirantes, 3900, Monte Alegre, Ribeirão Preto, SP, Brasil, CEP: 14040-905. E-mail: shnakao@usp.br 


\section{Introdução}

As empresas brasileiras de capital aberto passaram a divulgar suas demonstrações financeiras de acordo com as International Financial Reporting Standards (IFRS), por meio do Comitê de Pronunciamentos Contábeis (CPC). Essa adaptação insere as companhias brasileiras nacionais e estrangeiras em um padrão global. As novas regras seguidas pelos contadores estipulam novas escolhas no momento de realizar as contabilizações, que podem afetar os níveis de gerenciamento de resultados.

Os gestores podem usar escolhas contábeis em benefício próprio e que, alinhando estas escolhas ao interesse da empresa, também trazem ganhos e aumentos de valor para a mesma. Fields, Lys e Vincent (2001, p. 260) entendem que "o gerenciamento de resultados (GR) é quando o gestor exerce seu poder discricionário sobre os números contábeis. Tal discrição pode ser para maximizar o valor da firma ou com objetivo oportunista”.

Portanto, as práticas contábeis caminham de acordo com o objetivo do agente ou do principal. Do lado do proprietário, há a tentativa de maximizar o valor da empresa e, portanto, as escolhas contábeis seriam tomadas para minimizar os custos de transação da firma. Do outro lado, há o gestor que usa práticas contábeis para maximizar os seus próprios interesses, ou seja, práticas oportunistas (Coelho e Lopes, 2007). Este último ocorre quando não há o alinhamento dos interesses entre o principal e o agente.

Já Healy (1996), acredita que o gestor pode agir ora em benefício da empresa ora em benefício próprio. Podem existir companhias que tentam minimizar os resultados tributáveis para pagar menos impostos; em outras, há práticas para elevar os lucros no intuito de alcançar as metas estabelecidas e as expectativas dos analistas de mercado para receber o bônus por este desempenho. Portanto, existem várias formas e incentivos para as práticas oportunistas, tanto por parte dos acionistas, dos gestores ou de interesse de ambos.

Para Lopes (2002), o gerenciamento de resultado por meio de atitudes oportunistas pode trazer prejuízos aos usuários da informação contábil. Uma das formas de perda que pode ocorrer, conforme Paulo (2007, p. 46), é que "os investidores não possuem informações confiáveis para auxiliá-los na decisão, analistas estimam resultados erroneamente e instituições de crédito não têm a real percepção sobre os riscos".

A contabilidade enviesada e facilmente manejável faz com que os usuários da informação não tenham confiança nas divulgações e esta situação prejudica o desenvolvimento do mercado de capitais, pois apenas os gestores teriam a informação que realmente representa a realidade econômica e financeira da empresa e não a gama de investidores, analistas, credores e usuários em geral.

A contabilidade tem como objetivo reduzir a assimetria informacional, diminuir os problemas de agência e contribuir para o desenvolvimento do mercado de capitais. A assimetria informacional existe quando uma das partes de uma transação possui mais informação do que outra. Nesse caso, os administradores e muitas vezes os acionistas controladores possuem mais informação do que os usuários externos e acionistas minoritários.

Conforme Tendeloo e Vanstraelen (2005), a adoção de IFRS coloca no mercado um sinal positivo de aumento na qualidade da demonstração contábil e de maior transparência.

Outro ponto a favor da implementação de IFRS está o argumento de Jeanjean e Stolowy (2008, p. 481) de que o compartilhamento de um padrão tornaria mais fácil a comparação do desempenho financeiro entre as empresas de diferentes países. Isso melhoraria a eficácia dos fundos internacionais e tornaria o mercado de capital mais eficiente, levando menos custo de capital para as empresas.

Portanto, devido ao fato de que muitas companhias estão presentes cada vez mais em diversas nações, há necessidade de comparabilidade das informações financeiras e isto leva a uma tendência de convergência mundial das demonstrações contábeis. Desta forma, pode facilitar a análise dos usuários da informação, já que as normas seriam iguais indiferentemente do país em que é divulgada.

Então, o aumento na qualidade e na transparência aliada a uma maior comparabilidade das demonstrações contábeis leva a uma consequente redução da assimetria informacional. Com isso, a adoção de IFRS deve gerar um impacto no GR das empresas de forma a reduzi-lo. 
Dechow, Ge e Schrand (2010) elaboraram um estudo com a revisão das proxies para determinar a qualidade dos resultados $(\mathrm{EQ})^{1}$. Foram examinados mais de 300 trabalhos, uma das proxies foi o GR que quando praticado reduz a qualidade da informação. Modelos de accruals foram utilizados para calcular o gerenciamento, consequentemente, também para definir EQ.

Para Barth, Landsman e Lang (2008), a alta qualidade dos resultados apresenta menos GR. No estudo calculou-se a qualidade contábil (AQ) ${ }^{2}$, que para sua operacionalização foram utilizados GR, value relevance, e timely loss recognition, comparados com a adoção das normas internacionais. Os autores verificaram que de forma geral a divulgação no IAS aumenta a AQ.

Portanto, como as normas internacionais impactam na qualidade da informação contábil (Barth, Landsman e Lang, 2008) e, considerando que uma das variáveis utilizada para definir qualidade dos resultados é o GR (Dechow, Ge e Schrand, 2010), o problema de pesquisa deste trabalho é: houve mudanças nos níveis de Gerenciamento de Resultados nas companhias de capital aberto no Brasil e que ocorreram em função da adoção das International Financial Reporting Standards?

Esse padrão internacional entrou parcialmente em vigor no Brasil a partir das inserções da Lei Federal no 11.638 (2007), que estende às sociedades de grande porte disposições relativas à elaboração e divulgação de demonstrações contábeis, e da Medida Provisória no 449/08 (2008) (convertida atualmente na Lei $n^{\circ} 11.941$ (2009)), que alteraram a Lei $n^{\circ} 6.404$ (1976). As IFRS entraram em vigor no Brasil também por meio da emissão dos pronunciamentos técnicos contábeis elaborados pelo Comitê de Pronunciamentos Contábeis (CPC) ${ }^{3}$, criado pelo Conselho Federal de Contabilidade, em 2005.

No ano de 2010, a norma contábil brasileira alinhou-se ao padrão internacional com a adoção completa de IFRS. É importante para a academia e para o mercado a realização de um estudo que analisa os impactos desta nova norma na qualidade e transparência da divulgação da informação contábil, pois sua compreensão auxilia na análise econômica e financeira das empresas. Segundo Dechow, Ge, Schrand (2010), os trabalhos realizados para verificar os impactos que a mudança regulatória causou no nível de qualidade da informação do lucro utilizam como indicador de mensuração o nível de GR, assim como no estudo desenvolvido por Kohlbeck e Warrfield (2010). Desta forma, analisar os sinais de GR nas demonstrações contábeis antes e após a aderência ao IFRS é uma forma de entender os impactos na qualidade da divulgação.

Almeida (2010, p. 106), não identificou estudos mostrando o efeito real desta mudança normativa. Em razão disso, é imprescindível que se realizem estudos para se compreender os impactos ocorridos deste marco legal no Brasil.

O objetivo desta pesquisa é verificar se houve mudança nos níveis de gerenciamento de resultados após 2010 e se foi em função da adoção completa de IFRS pelas companhias brasileiras de capital aberto.

A abordagem do problema foi tratada por meio de uma pesquisa empírica, com o emprego de instrumentos estatísticos no tratamento dos dados. A amostra composta pelas companhias brasileiras de capital aberto foi coletada do Economática e da Comissão de Valores Mobiliários (CVM), no período de 2006 a 2011. Aplicou-se o Modelo de Jones Modificado (Dechow, Sloan e Sweenwy, 1995), como proxy para os accruals discricionários. Primeiramente, verificou-se se houve mudança nos níveis de accruals discricionários após 2010, em que ocorreu a adoção completa de IFRS pelas empresas brasileiras. Posteriormente, a variável de accruals discricionários, além de mais quatro variáveis de controle, foi inserida no Modelo de Mcnichols e Wilson (1988), que foi adaptado, neste trabalho, para verificar se a adoção de IFRS provocou mudanças nos accruals discricionários. A técnica estatística empregada foi a de regressão com dados em painel.

\footnotetext{
Termo utilizado nas referências internacionais para definir qualidade dos resultados.

Termo utilizado nas referências internacionais para definir qualidade contábil.

O comitê é composto por representantes da Associação Brasileira das Companhias Abertas (Abrasca), Associação dos Analistas e Profissionais de Investimento do Mercado de Capitais (Apimec), Bolsa de Valores e Mercadorias e Futuros (BM\&FBOVESPA), Conselho Federal de Contabilidade (CFC), Fundação Instituto de Pesquisas Contábeis, Atuariais e Financeiras (Fipecafi) e Instituto dos Auditores Independentes do Brasil (Ibracon).
} 
O trabalho está estruturado da seguinte maneira: na seção dois, é apresentado o referencial teórico, com os trabalhos relacionando GR com IFRS, as peculiaridades do Brasil e a hipótese do trabalho. Na seção três, apresenta-se a metodologia divida em três partes: procedimentos metodológicos adotados no trabalho com a descrição do modelo utilizado, em seguida as variáveis empregadas e, terminando com a composição da amostra. Na seção quatro, são apresentados os resultados da pesquisa. Para finalizar, na seção cinco estão as considerações finais.

\section{Referencial Teórico}

\subsection{Teoria da Agência}

Esta teoria tem como principal trabalho de referência o de Jensen e Meckling (1976), que elaboram um raciocínio sobre a relação entre o agente (gestor) e o principal (acionista). Os autores propuseram um conflito de interesse entre as partes, pois existem decisões que podem maximizar a riqueza de um lado e outras que aperfeiçoam a do outro.

Devido à impossibilidade de contrato completo e de agentes perfeitos, a empresa fica aberta à decisão do gestor que pode ser voltada ao seu próprio objetivo e não ao da empresa. O problema de agência parte do pressuposto de que não existe informação igualmente distribuída entre os agentes, de forma que aquele que detém mais informação pode tomar decisões oportunistas e voltadas aos seus interesses particulares. Outro ponto é o moral hazard, ou risco moral, que abrange casos em que as ações do agente não são observadas pelo principal ou são onerosas (sem custo-benefício) para serem monitoradas.

Diante dessa situação, a assimetria de informação gera ineficiências de mercado (Akerlof, 1970), dado que cada agente toma uma decisão embasando-se nas suas informações disponíveis e aqueles que detêm mais informações podem tirar proveito dessa vantagem. Para reduzir o conflito de interesse, existe a possibilidade de criar mecanismos para alinhar o interesse das partes e monitorar a ação do agente, ou seja, todas essas ações têm um preço, que é definido como custo da agência.

Para reduzir as atitudes que maximizem o valor do agente, é necessário um maior custo com monitoramento das atividades do mesmo. Conforme Cardoso, Saraiva, Tenório e Silva (2009, p. 794), "a contabilidade é um mecanismo dedicado à redução da assimetria informacional". Portanto, quanto menor a assimetria, menores os custos, pois não há a necessidade de outros mecanismos para se obter a informação real, já que as demonstrações deveriam representar de forma fidedigna a realidade financeira da empresa.

\subsection{Gerenciamento de Resultados}

Os gestores possuem incentivos para adequar as informações de modo com que ele obtenha um ganho. O gestor pode alterar, ou melhor, fazer escolhas contábeis para aumentar ou alcançar a sua meta e desta forma conseguir o seu bônus (Healy, 1985). A firma, quando faz contratos de dívidas com cláusulas que estabelecem valores ou condições para que o empréstimo seja liberado ou para que continuem com limites vigentes, é capaz de levar os administradores e proprietários a manipulações contábeis principalmente quando estão na eminência de não conseguir manter os acordos (Sweeney, 1994).

Estas manipulações e escolhas contábeis são definidas na literatura como gerenciamento de resultado (GR), que acontece quando as informações contábeis não representam a realidade e isto pode influenciar a tomada de decisão dos usuários da informação de forma errada. Uma das causas do GR é que as firmas tentam evitar a divulgação de perdas. Outra possibilidade é minimizar a volatilidade dos resultados. As companhias com resultados menos voláteis dão uma segurança maior para o usuário, pois a projeção do lucro é mais fácil de ser feita quando não há muita oscilação. Mais segurança torna a empresa com menos risco o que melhora a relação risco-retorno, valorizando assim as companhias. 


\subsection{Gerenciamento de Resultado e IFRS}

De acordo com Defond (2010), os estudos que analisam a qualidade da informação contábil no período de transição das normas locais para IFRS são pesquisas potenciais futuras. Como GR é um teste para qualidade da informação, o número de pesquisas nesta área tende a crescer.

Algumas já foram feitas, como Tendeloo e Vanstraelen (2005), que analisaram se a adoção voluntária da norma internacional reduz o nível de GR na Alemanha. Porém, não é encontrada essa relação em sua mensuração. Ressaltaram, também, que o estudo foi desenvolvido com empresas de um país code-law com baixa proteção ao investidor. Tendeloo e Vanstraelen (2005) utilizaram como variáveis de controle o tamanho da empresa, fluxo de caixa operacional e endividamento para cálculo da regressão. Também usaram uma dummy para as empresas auditadas pelas Big Four (as 4 maiores empresas de auditoria do mundo), além de inserir uma dummy por setor e outra conforme o local em que suas ações estavam listadas. Foi observado em seu estudo que as empresas que divulgavam em IFRS em comparação com as que usaram a norma da Alemanha, aumentaram os accruals discricionários. Porém, em companhias auditadas pelas 4 maiores empresas do setor no mundo houve redução do GR. Desta forma, chegam a conclusão que não há diferença no GR entre as empresas que divulgam em IFRS e no padrão de divulgação da Alemanha.

Barth, Landsman e Lang (2008) examinaram se a aplicação de normas internacionais está associada com o aumento na qualidade da contabilidade (accounting quality). Em seu estudo foi evidenciado que 21 países apresentaram, após a alteração do padrão contábil, menor GR, o qual foi utilizado como proxy para captar a melhoria na qualidade.

Jeanjean e Stolowy (2008) analisaram o efeito de IFRS no nível de GR. A amostra foi composta de empresas da Austrália, da França e do Reino Unido. Os resultados encontrados na Austrália e Reino Unido foram de que o nível de GR diminuiu após a introdução de IFRS, estes que são países common-law. Já na França, um país code-law, o resultado foi de que o padrão internacional aumentou os indícios de GR.

Conforme Iatridis (2012) o Brasil está enquadrado como um país code-law. Segundo Martins, Martins, Martins (2007) o Brasil mantém o processo normativo contábil realizado pelo Estado, assim como na França e na Alemanha, que realizam suas demonstrações conforme disposição legal dada pelo Estado. Dessa forma, são considerados países code-law.

Chegando ao enquadramento do Brasil como um code-law e, esperando o mesmo resultado de Jeanjean e Stolowy (2008) é previsto que a adoção das normas internacionais aumente os indícios de GR. Porém, como já citado neste trabalho, o IFRS tende a melhorar a qualidade da informação contábil, aumentar a comparabilidade e, assim, reduzir o GR.

Iatridis (2010) desenvolveu um trabalho no Reino Unido analisando o nível de GR nos anos de mudança do UKGAAP para IFRS, e verificou que a implementação da norma internacional reduziu os níveis de GR. Iatridis e Rouvolis (2010), também realizaram o mesmo estudo na Grécia e chegaram à mesma conclusão, de que o IFRS reduziu os indícios de GR.

No estudo realizado por Elbannan (2011), foi verificado o impacto da aderência da nova norma na qualidade do resultado. O autor analisou se as empresas do Egito, após a adoção do International Accounting Standards (IAS), tiveram seus índices de GR reduzidos, no pressuposto de que a alta qualidade de resultado é evidenciada por baixo GR; porém, não foi encontrado resultado significativo.

Portanto, trabalhos internacionais verificam o impacto que a mudança na regulamentação contábil para o padrão internacional tem sobre o nível de GR nas empresas, ou qual a influência na qualidade da informação contábil ou nos resultados das demonstrações (earnings quality), utilizando como proxy o GR. De acordo com os estudos anteriormente citados, foi concluído que a adoção de IFRS reduz a manipulação de resultados. Porém, no trabalho de Elbannan (2011), não foi possível alegar com significância estatística a mesma mudança. Considerando a diversidade de resultados encontrados nos países que fizeram estudos com os mesmos objetivos, aumenta a importância de pesquisas no Brasil para examinar qual o comportamento adotado. 


\subsection{Gerenciamento de Resultado e IFRS - Contexto brasileiro}

O Brasil, nos últimos anos, expandiu o mercado de capital com as emissões de novas ações e abertura de capital de empresas fechadas, com a entrada de recursos estrangeiros e com a maior aplicação dos brasileiros nesta modalidade de investimento. Para um mercado sólido e transparente, é necessário que as informações representem a realidade com fidedignidade, garantindo maior segurança aos investidores. Conforme Easley e O’Hara (2004), uma informação contábil mais precisa reduz o risco do investidor. Desse modo, parece haver uma relação entre a qualidade da informação divulgada e o retorno exigido dos fornecedores de recursos.

De acordo com Campos (2006, p. 374), "na média, o acionista majoritário possui 61,01\% das ações ordinárias, indicando assim que é um resultado importante para demonstrar o alto grau de concentração da propriedade das empresas brasileiras." Um acionista que detém controle sobre as ações da companhia, pode agir em beneficio próprio em detrimento aos demais. Uma das formas de minimizar a assimetria de informação, protegendo assim o acionista minoritário, pode ser a contabilidade.

A Lei $n^{\circ} 11.638$ (2007) estabeleceu a neutralidade tributária, reduzindo o impacto da contabilidade elaborada para o fisco sobre a contabilidade financeira. Antes a divulgação para o mercado de capitais e para o governo era a mesma, isto levava as empresas a apresentarem uma demonstração que favorecia o pagamento mínimo de tributos. Desta forma, a ligação da contabilidade ao fisco fazia com que o resultado ficasse distorcido devido a um incentivo econômico que existe nesta relação.

O estímulo existente é o que visa minimizar o pagamento de tributos da empresa, para isso os gestores escolhem práticas contábeis que alcancem este objetivo (Goncharov e Zimmermann, 2006). Porém, mesmo que o lucro contábil seja diferente do lucro fiscal, não se pode afirmar que a contabilidade financeira seja independente da tributária, no Brasil. Afinal, para que uma despesa seja dedutível (contabilidade tributária) é necessário que tenha sido contabilizada (Cardoso, 2005, p. 101).

Portanto, mesmo com o fim deste incentivo existem outros, que podem ser desenvolvidos com o fim da ligação entre o fisco e a contabilidade para a prática de GR. Conforme Watts e Zimmerman (1990), a hipótese dos custos políticos e do plano de bônus são algumas das possibilidades. O primeiro ocorreria para não chamar a atenção do fisco com uma grande diferença entre os dois lucros, o que poderia causar uma criação de mecanismos para aumentar a tributação; o segundo aconteceria para aumentar o lucro divulgado, o bônus dos gestores e o valor da empresa. Portanto, retirando o incentivo dos tributos, voltam-se a atenção para outros.

Contudo, como as IFRS têm o objetivo de melhorar a divulgação contábil e tornar a informação mais relevante para os investidores, a adoção tenderia à redução do potencial de GR nas demonstrações das companhias (Iatridis, 2010). Então, foi elaborada a seguinte hipótese de pesquisa: houve uma redução nos níveis de GR no Brasil ocorrida em função da adoção de IFRS.

\section{Metodologia}

\subsection{Procedimentos Metodológicos}

Os modelos de mensuração da variável gerenciamento de resultado, na maioria dos trabalhos, tratam dos accruals discricionários, que pressupõe que seja referente somente a manipulação da informação contábil. Os accruals não discricionários são os inerentes à atividade da empresa; portanto, estes não sofrem alterações por escolhas contábeis que favoreçam uma das partes envolvidas. Enfim, a soma dos dois representa os accruals totais, que é a diferença entre entre fluxo de caixa e o lucro da empresa. Esta operação é descrita na equação a seguir: 


$$
\mathrm{AT}_{\mathrm{t}}=\mathrm{AD}_{\mathrm{t}}+\mathrm{AND}_{\mathrm{t}}
$$

Em que:

$\mathrm{AT}_{\mathrm{t}}=$ Accruals Totais da empresa no período $t$.

$\mathrm{AD}_{\mathrm{t}}=$ Accruals Discricionários da empresa no período $t$.

ANDt $=$ Accruals não discricionários da empresa no período t.

O cálculo dos accruals totais é realizado conforme Healy (1985) e Jones (1991):

$$
\mathrm{AT}=\Delta(\mathrm{Ac}-\mathrm{Disp})-\Delta(\mathrm{Pc}-\text { EmprCP })-\text { DespDepr }
$$

Em que:

$\mathrm{AT}=$ Accruals Totais da empresa no período

Ac $=$ Ativo circulante

Disp $=$ Disponibilidade e aplicações financeiras de curto prazo

$\mathrm{Pc}=$ Passivo circulante

EmprCP = empréstimos e financiamentos de curto prazo

DespDepr $=$ despesas com depreciação, amortização.

Como proxy de GR é definido o cálculo dos accruals discricionários, e para isso foi utilizado o Modelo de Jones Modificado. Em seguida, esta variável é inserida, juntamente com as demais, em uma equação, cujo modelo preliminar foi sugerido por McNichols e Wilson (1988).

De acordo Martinez (2001, p. 41), o Modelo de Jones é o mais utilizado em pesquisas de GR. A seguir na Equação 3 é apresentada a fórmula de regressão linear, conforme o Modelo de Jones (1991):

$$
\mathrm{AT}_{\mathrm{i}, \mathrm{t}}=\alpha_{1}\left(1 / \mathrm{A}_{\mathrm{i}, \mathrm{t}-\mathrm{1}}\right)+\alpha_{2} \Delta \operatorname{Recliq}_{\mathrm{i}, \mathrm{t}}+\alpha_{3} \Delta \operatorname{Imob}_{\mathrm{i}, \mathrm{t}}+\mathrm{e}_{\mathrm{i}, \mathrm{t}}
$$

Em que:

$\mathrm{AT}_{\mathrm{i}, \mathrm{t}}=$ accruals ponderados pelo total de ativos no final do período $t-1$;

$\mathrm{A}_{\mathrm{i}, \mathrm{t}-\mathrm{1}}=$ Total de Ativos no ano $\mathrm{t}-1$;

$\Delta \operatorname{RecLiq}_{\mathrm{i}, \mathrm{t}}=$ variação da receita líquida ponderada pelo total de ativos no final do período $t-1$;

$\mathrm{Imob}_{\mathrm{i}, \mathrm{t}}=$ imobilizado e diferido/intangível ponderados pelo total de ativos no final do período $t-1$; $\mathrm{e}_{\mathrm{i}, \mathrm{t}}=$ erro, resíduos.

Porém, é preciso evoluir nas proxies para o cálculo de accruals discricionários segundo Defond (2010, p. 407) mesmo sendo um modelo aceito como proxy de qualidade de resultado. O cálculo do AD, pelo Modelo de Jones, é criticado por pesquisas internacionais que questionam a capacidade de dividir corretamente a parte gerenciada e a inerente a atividade da empresa. (Subramanyam, 1996).

Então, o trabalho da Dechow, Sloan e Sweeney (1995) modifica o modelo levando em consideração em sua fórmula a variação no contas a receber juntamente com a diferença entre as vendas do período e do ano anterior. Desta forma, a inserção na equação do contas a receber faz com que a manipulação que ocorre nas vendas a prazo é entendida com prática de GR. Esta alteração aumentou a eficácia dos testes do modelo. Além disso, conforme Paulo (2007, p. 103) o modelo usado na maioria dos trabalhos empíricos é o de Jones Modificado. Guay, Kothari e Watts (1996, p. 86) chegam a seguinte consideração quanto aos modelos empregados: "Regressões simples de retorno sobre os accruals discricionários sugerem que os Modelos de Jones e Jones Modificado produzem accruals discricionários que são consistentes tanto com a melhora do desempenho quanto com a suavização oportunista dos lucros". 
De acordo com Xiong (2006, p. 217), as mudanças no ambiente econômico e a política de crédito da empresa são controladas na fórmula de Jones Modificado, que é apresentada a seguir conforme Dechow, Sloan e Sweeney (1995):

$$
\operatorname{AND}_{\mathrm{i}, \mathrm{t}}=\alpha_{1}\left(1 / \mathrm{A}_{\mathrm{i}, \mathrm{t}-\mathrm{-}}\right)+\alpha_{2}\left(\Delta \operatorname{Recliq}_{\mathrm{i}, \mathrm{t}-} \Delta \operatorname{ContRec}_{\mathrm{i}, \mathrm{t}}\right)+\alpha_{3} \Delta \operatorname{Imob}_{\mathrm{i}, \mathrm{t}}
$$

Em que:

$\mathrm{AND}_{\mathrm{i}, \mathrm{t}}=$ accruals não discricionários da empresa $i$ no período $t$;

$\mathrm{A}_{\mathrm{i}, \mathrm{t}-\mathrm{1}}=$ Total de Ativos no ano $t-1$;

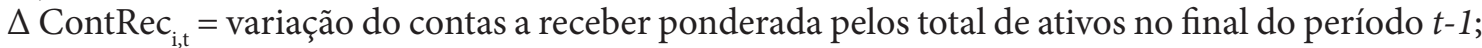

$\Delta \operatorname{Recliq}_{\mathrm{i}, \mathrm{t}}=$ variação da receita líquida ponderada pelos total de ativos no final do período $t-1$;

$\operatorname{Imob}_{\mathrm{i}, \mathrm{t}}=$ imobilizado e diferido/intangível ponderados pelos total de ativos no final do período $t-1$; $\alpha_{1}, \alpha_{2}, \alpha_{3}=$ coeficientes estimados na Equação 3.

No Modelo de Jones (1991), os accruals discricionários são extraídos dos resíduos da regressão. Já no Modelo de Jones Modificado, primeiramente são calculados os coeficientes na Equação 3, depois estes coeficientes são combinados na Equação 4, estimando os accruals não discricionários (AND). Finalmente, o AD é calculado conforme a Equação 1.

Nesta pesquisa, diferentemente do método utilizado pela Kothari, Leone e Wasley (2005), que apresenta cortes transversais, e por Dechow, Sloan e Sweeney (1995), que apresenta séries temporais, o modelo foi calculado com os dados em painel.

Com o valor de $\mathrm{AD}$ definido, foram realizados dois testes. O primeiro procura verificar, por meio de teste de hipótese de diferença de médias, se os níveis de AD são diferentes antes e após 2010, ano em que houve a adoção de IFRS. Como é possível que esses níveis não sejam diferentes em função do evento da adoção de IFRS em si, realizou-se um teste de regressão considerando uma variável dummy para o evento como explicativa da variável dependente $\mathrm{AD}$.

Para o teste de hipótese de diferença de médias, foi calculado o AD de cada empresa-ano de acordo com o modelo de Jones Modificado, que foram então separado em dois grupos, antes e após 2010. Foi realizado o teste não paramétrico U de Mann-Whitney, com intervalo de significância de 5\%.

A variável $\mathrm{AD}$ também foi inserida na Equação 5, que é uma fórmula adaptada do modelo geral de McNichols e Wilson (1988). Foi utilizada como variável relacionada com GR à adoção ou não de IFRS, que é representada com uma dummy, ou seja, há dois grupos: um é o período em que há a adoção completa às IFRS e outro em que ainda não há a obrigatoriedade plena. Além disso, foram inseridas variáveis de controle no modelo proposto. Segue a fórmula para o cálculo de regressão:

$$
\text { AD: } \alpha_{0}+\alpha_{1} \operatorname{IFRS}_{i, t}+\alpha_{2} \text { ENDI }_{i, t}+\alpha_{3} \operatorname{ROA}_{i, t}+\alpha_{4} \mathrm{FCOP}_{i, t}+\alpha_{5} \operatorname{TAM}_{i, t}+e_{i, t}
$$

Em que:

$\mathrm{AD}=$ accruals discricionários calculados pelo Modelo de Jones Modificado;

IFRS $_{\mathrm{i}, \mathrm{t}}=$ variável dummy que indica se a divulgação financeira está no padrão internacional; caso sim, IFRS ${ }_{\mathrm{i}, \mathrm{t}}=1$, caso contrário, IFRS ${ }_{\mathrm{i}, \mathrm{t}}=0$ (no estudo foram consideradas as demonstrações de 2010 e $2011=1,2006,2007,2008$ e $2009=0$ );

$\mathrm{ENDIV}_{\mathrm{i}, \mathrm{t}}=$ Endividamento da empresa no período;

$\mathrm{ROA}_{\mathrm{i}, \mathrm{t}}=$ Retorno sobre o ativo;

$\mathrm{FCOP}_{\mathrm{i}, \mathrm{t}}=$ Fluxo de caixa operacional proporcional pelo total de ativos;

$\mathrm{TAM}_{\mathrm{i}, \mathrm{t}}=$ logaritmo natural do ativo das empresas;

$\mathrm{e}_{\mathrm{i}, \mathrm{t}}=$ erro, resíduo. 
Toda a análise dos dados com regressão com dados em painel foi desenvolvida por meio do STATA versão 9.2.

\subsection{Definição das Variáveis}

Além da variável dependente $\mathrm{AD}$ (accruals discricionários) e da dummy IFRS, este trabalho contou em seu modelo com as variáveis de controle: Endividamento (ENDIV), Desempenho (ROA - retorno sobre o ativo), Fluxo de Caixa Operacional (FCOP) e Tamanho (TAM). A seguir são apresentados os embasamentos teóricos para inserção das mesmas no modelo proposto.

Endividamento é uma variável utilizada em pesquisas internacionais como variável de controle para gerenciamento de resultados (Gu, Lee e Rosett, 2005). Dhaliwal (1980) analisou o efeito de atitudes gerenciais em relação ao normativo contábil sob a perspectiva da estrutura capital. Comprovou a hipótese de que, quanto maior o nível de endividamento, maior é o uso de métodos contábeis fora do alinhamento normativo.

Watts e Zimmerman (1990) dizem que quanto maior a dívida, mais os gestores usam de técnicas contábeis para aumentar o resultado. De acordo com trabalho de Defond e Jiambalvo (1994), um alto nível de dívida pode levar a um GR com objetivo de aumentar o resultado para evitar uma falência técnica. Ou seja, gestores visando a continuidade da empresa e dos contratos com seus credores fazem uso de artifícios contábeis para manipular as informações das demonstrações.

Conforme Valle (2008, p. 61), a variável endividamento foi calculada em relação ao passivo oneroso total, de curto prazo e de longo prazo. A medida que revela dependência financeira da empresa em relação aos recursos de terceiros é formulada da seguinte forma:

$$
\text { ENDIV = Passivo Oneroso / Ativo }
$$

(Equação 6)

$\mathrm{Na}$ Equação 6, Passivo Oneroso corresponde aos financiamentos e empréstimos de curto prazo, financiamentos e empréstimos de longo prazo, debêntures de curto prazo e debêntures de longo prazo.

Outra variável inserida é o desempenho que segundo Kothari, Leone e Wasley (2005), o cálculo dos accruals discricionários quando encorpado a esta variável, aumenta a confiabilidade e o poder preditivo de GR. Francis, Lafond, Olsson e Schipper (2005) também fizeram uso do desempenho como variável na regressão de custo da dívida nos accruals, e utilizaram como proxy o retorno sobre o ativo (ROA).

Para o cálculo neste estudo, é considerado o desempenho da empresa levando em conta todas as fontes de financiamento, ou seja, o resultado da empresa, dividido pelo total de ativos. Essa medida de performance é recomendada, visto que os ativos são os benefícios econômicos futuros da companhia. Conforme Kothari, Leone e Wasley (2005), é utilizado o ROA como proxy de performance com a seguinte fórmula:

$$
\text { ROA = Lucro Líquido / Ativo }
$$

A terceira variável do modelo é o fluxo de caixa operacional. Pae (2005) verificou que o poder preditivo do Modelo de Jones (1991) e Jones Modificado aumenta com a inclusão do FCOP. Além desta pesquisa, outros estudos como os de: Dechow e Dichev (2002); Francis et al. (2005); Gu, Lee e Rosett (2005); Barth, Landsman e Lang (2008); e Iatridis (2010) fizeram a associação entre os accruals discricionários e o fluxo de caixa operacional.

Conforme Land e Lang (2002) e Myers, Myers e Skinner (2007), a prática de income smoothing induz uma correlação negativa maior entre fluxo de caixa e accruals, pois segundo Leuz, Nanda e Wysocki (2003, p. 510) gestores também podem usar seu critério contábil para esconder choques econômicos para o fluxo de caixa operacional da empresa. Por exemplo, eles podem acelerar a divulagação de receitas futu- 
ras ou atrasar a declaração dos custos atuais para esconder o baixo desempenho atual. Por outro lado, os gestores podem não relatar o bom desempenho corrente para criar reservas para o futuro. Em ambos os casos, é resultante uma correlação negativa entre os accruals e os fluxos de caixa operacional.

Outra variável muita utilizada em pesquisas nacionais e internacionais é o tamanho da empresa. De acordo com Gu, Lee e Rosett (2005, p. 317): “tamanho é uma das mais importantes características da empresa”. Eles argumentam sua ligação negativa com os accruals segundo três particularidades: as grandes empresas (em relação às pequenas) têm mais benefícios relativos à economia de escala; são mais maduras e operam em um estado mais estacionário; elas tendem a ser mais diversificadas, operando em mais setores. Todas estas características levam a uma menor volatilidade operacional e, consequentemente, a uma menor variabilidade de accruals.

Os trabalhos de Gu, Lee e Rosett (2005) e Tendeloo e Vanstraelen (2005) chegaram ao resultado de que a variação dos accruals diminui de acordo com o tamanho da empresa, ou seja, possui um coeficiente negativo.

De acordo com Francis et al. (2005), Gu, Lee e Rosett (2005) e Tendeloo e Vanstraelen (2005, p. 165), a medida utilizada para definir tamanho é o logaritmo do ativo total. Com isso, a variável tamanho é representada da seguinte forma:

$$
\operatorname{TAM}_{\mathrm{i}, \mathrm{t}}=\operatorname{LogAt}_{\mathrm{i}, \mathrm{t}}
$$

Em que:

$\log A t_{i, t}=\operatorname{logaritmo~do~ativo~total~da~empresa~} i$ no período $t$

\subsection{Amostra}

A pesquisa é limitada às demonstrações contábeis presentes no banco de dados da Economática e da CVM. O período de análise compreende o intervalo entre os anos de 2006 e $2011^{4}$.

Para o cálculo dos accruals no modelo selecionado, são utilizadas variáveis do período anterior. Desse modo, foram extraídos os dados da Economática em que as empresas divulgam as informações do ano vigente mais as do ano anterior na mesma regra contábil. Para aumento da quantidade de observações, foram definidas as divulgações trimestrais. A amostra foi coletada em abril de 2012.

Para realizar este trabalho, foi estabelecida uma quantidade mínima de observações por companhia. A primeira amostra foi baseada em todos os dados coletados, menos as empresas que não publicaram as informações necessárias ${ }^{5}$ para a realização do estudo em pelo menos 8 observações, pois segundo Dechow e Dichev (2002, p. 42), são necessários pelo menos oito períodos de dados para estimar regressões das características específicas das empresas. Portanto, a amostra ficou reduzida, como demonstrada na Tabela 1.

Tabela 1

Amostra de empresas

\begin{tabular}{lc}
\hline \multicolumn{1}{c}{ Sample } & Number of companies \\
\hline Initial sample & 333 \\
\hline Companies with less than eight observations & 59 \\
\hline Final sample & 274 \\
\hline
\end{tabular}

4 Os filtros colocados para se obter a amostra inicial foram: País sede: Brasil; Tipo de ativo: ações; Ativo ou cancelado: ativo; Data base: informação trimestral; Bolsa: Bovespa; Mostrar apenas informação do ativo de maior liquidez; Consolidado, caso não tenha, usar dados da demonstração individual; Foram excluídas as empresas classificadas como financeiras, seguradoras e fundos, pois suas demonstrações são diferentes das demais firmas em termos de apresentação e regras. Enfim, não há comparabilidade.

5 Dados necessários: ativo total, receita líquida, imobilizado, fluxo de caixa operacional (empresas que não divulgaram foi montado o fluxo de caixa pelo método indireto), lucro líquido. As observações em que alguma destas informações não foi apresentada foram retiradas da amostra. 
Para a análise, a amostra foi dividida em dois períodos: Antes da Mudança (2006-2009), incluindo o período de pré-adoção, que compreende a fase de transição da norma antiga para a internacional; e o período IFRS (2010-2011), em que as demonstrações foram divulgadas completamente na nova norma. Justifica-se esse corte de períodos, sem considerar o período de pré-adoção em separado, em função do objetivo de verificar o gerenciamento de resultados antes e após a adoção de IFRS, o que só pode ser considerada após a adoção completa em 2010.

\section{Resultados e Discussão}

O primeiro procedimento foi elaborar o cálculo de Jones Modificado para determinar o AD. Para isso, foi feito o cálculo dos coeficientes no Modelo de Jones (1991) (Equação 3) com a inclusão de uma constante. Seguem na Tabela 2 os coeficientes utilizados no Modelo de Jones Modificado.

Tabela 2

Coeficientes do Modelo de Jones (1991)

\begin{tabular}{|c|c|c|}
\hline Variáveis explicativas & Coeficiente & $\mathbf{z}$ \\
\hline $1 / \mathrm{A}_{\mathrm{i}, \mathrm{t}-1}$ & 38913,26 & $39,27 * * *$ \\
\hline$\Delta$ Recliq $_{\mathrm{i}, \mathrm{t}}$ & 0,0451832 & $5,43 * \star \star$ \\
\hline$\Delta \mathrm{Imob}_{\mathrm{i}, \mathrm{t}}$ & $-0,0747181$ & $-52,08 * \star *$ \\
\hline Constante & $-0,2379228$ & $-1,02 * \star \star *$ \\
\hline $\mathrm{R}^{2}$ & 0,6054 & \\
\hline Estatística F & $4734,65 * \star *$ & \\
\hline
\end{tabular}

Como observado na Tabela 2, todos os coeficientes apresentaram significância estatística a 1\%. Além disso, o $\mathrm{R}^{2}$ também foi significativo e exibiu uma alta relação entre as variáveis dependentes e independentes.

Em seguida, estes coeficientes foram combinados na Equação 4, estimando os accruals não discricionários (AND) e, finalmente, o $\mathrm{AD}$ é calculado conforme Equação 1. Esta variável é a dependente no modelo proposto (Equação 5) e, para todos os cálculos a seguir, o AD está inserido em módulo, pois mensura-se a amplitude de GR nas empresas e não se ele é negativo ou positivo. As variáveis independentes são: IFRS, ENDIV, ROA, FCOP e TAM. Segue a estatística descritiva das mesmas na Tabela 3.

Tabela 3

Análise descritiva da amostra

\begin{tabular}{|c|c|c|c|c|}
\hline Variáveis & Desvio Padrão & Média & Mínimo & Máximo \\
\hline$A D$ & 12,89032 & 0,7419408 & 0,0000074 & 623,2941 \\
\hline IFRS $_{i, t}$ & 0,4756506 & 0,3456311 & 0 & 1 \\
\hline Endiv $_{i, t}$ & 9,295065 & 0,932395 & 0 & 212,6818 \\
\hline $\mathrm{ROA}_{\mathrm{i}, \mathrm{t}}$ & 0,1390595 & $-0,0027725$ & $-2,16093$ & 1,596396 \\
\hline $\mathrm{FCOP}_{\mathrm{i}, \mathrm{t}}$ & 0,1710717 & 0,0092481 & $-2,564648$ & 1,225489 \\
\hline $\operatorname{Tam}_{\mathrm{i}, \mathrm{t}}$ & 0,854791 & 6,084745 & 3,254065 & 8,796329 \\
\hline
\end{tabular}


O teste Kolmogorov-Smirnov foi selecionado para constatar se as variáveis possuem uma distribuição normal. É relevante esta constatação, pois influencia na escolha dos testes estatísticos. A hipótese nula sugere uma distribuição normal. Porém, os testes rejeitam a hipótese de normalidade de todas as variáveis, conforme a Tabela 4.

Tabela 4

Teste Kolmogorov-Smirnov

\begin{tabular}{|c|c|}
\hline Variáveis & z \\
\hline$A D$ & $0,4492 * * *$ \\
\hline IFRS $_{i, t}$ & $0,4206^{* * *}$ \\
\hline Endiv $_{i, t}$ & $0,4643 * * *$ \\
\hline $\mathrm{ROA}_{\mathrm{i}, \mathrm{t}}$ & $0,3273 * * *$ \\
\hline $\mathrm{FCOP}_{\mathrm{i}, \mathrm{t}}$ & $0,3057^{* * *}$ \\
\hline $\operatorname{Tam}_{\mathrm{i}, \mathrm{t}}$ & $0,0224 *$ \\
\hline
\end{tabular}

Com a variável $\mathrm{AD}$ calculada e os testes de distribuição normal, foi realizado primeiramente o teste de hipótese de diferença de médias para verificar se houve mudança nos níveis de GR após 2010, ano da adoção completa de IFRS. Na Tabela 5, seguem os resultados do teste U Mann-Whitney.

Tabela 5

Teste U de Mann-Whitney entre GR e IFRS

\begin{tabular}{cccc}
\cline { 2 - 4 } & $\begin{array}{c}\text { Média } \\
\text { sem IFRS }\end{array}$ & $\begin{array}{c}\text { Média } \\
\text { com IFRS }\end{array}$ & $\mathbf{Z}$ \\
\hline $\mathrm{AD}$ & 0,9945 & 0,2638 & $7,287^{\star * *}$ \\
\hline
\end{tabular}

Como pode ser observado, os AD foram reduzidos significativamente após 2010, ano da adoção de IFRS, ou seja, existiu uma redução do nível de GR no período em que as demonstrações contábeis foram publicadas em aderência às normas internacionais. Há evidência estatística de diferença de média entre os grupos (sem IFRS - dummy 0 - e com IFRS - dummy 1), pois a estatística Z é significante.

Em seguida, para a análise do impacto do evento da adoção de IFRS sobre os $\mathrm{AD}$, foram realizados os cálculos do modelo proposto (Equação 5) com efeitos fixos, efeitos aleatórios, os testes de heterocedasticidade, de correlação serial, de multicolinearidade e o modelo corrigido com estimadores robustos na presença de heterocedasticidade e correlação serial, por meio da correção de Newey e West (1987). Segue a Tabela 6 com todos estes resultados. 
Tabela 6

\section{Resultados do Modelo Proposto}

\begin{tabular}{|c|c|c|c|c|c|c|}
\hline \multirow{2}{*}{ Variáveis explicativas } & \multicolumn{2}{|c|}{ Efeitos fixos } & \multicolumn{2}{|c|}{ Efeitos aleatórios } & \multicolumn{2}{|c|}{ Modelo Corrigido } \\
\hline & Coeficiente & $\mathbf{t}$ & Coeficiente & $\mathbf{z}$ & Coeficiente & $\mathbf{z}$ \\
\hline IFRS $_{i, t}$ & 1,306644 & $2,24^{* *}$ & $-0,6387946$ & $-1,35$ & 1,306644 & 1,59 \\
\hline Endiv $_{i, t}$ & 0,0520056 & 0,68 & 0,0728393 & $1,75^{\star}$ & 0,0520056 & 1,91 * \\
\hline $\mathrm{ROA}_{i, t}$ & $-1,182189$ & $-0,43$ & $-1,546022$ & $-0,59$ & $-1,182189$ & 0,231 \\
\hline $\mathrm{FCOP}_{i, t}$ & 1,85186 & 0,93 & 0,5239727 & 0,27 & 1,885186 & 1,61 \\
\hline $\operatorname{Tam}_{\mathrm{i}, \mathrm{t}}$ & $-10,07194$ & $-5,94 * * *$ & $-0,5485586$ & $-1,42$ & $-10,07194$ & $-1,88^{*}$ \\
\hline Constante & 61,50633 & $6,02 * * *$ & 4,221901 & $1,79 *$ & & \\
\hline $\mathrm{R} 2$ & \multicolumn{2}{|c|}{0,0014} & \multicolumn{2}{|c|}{0,0054} & \multicolumn{2}{|c|}{0,0139} \\
\hline Estatística F/x2 & \multicolumn{2}{|c|}{$7,94 * \star *$} & \multicolumn{2}{|c|}{$12,76 * *$} & \multicolumn{2}{|c|}{$8,1 * * *$} \\
\hline Heterocedasticidade & 17000000 & $\star \star \star$ & 168,41 & & & \\
\hline Correlação Serial & \multicolumn{4}{|c|}{$59,596 * * *$} & & \\
\hline Multicolinearidade & \multicolumn{4}{|c|}{1,66} & & \\
\hline Hausman & \multicolumn{4}{|c|}{$34,95 * * *$} & & \\
\hline Observações & \multicolumn{4}{|c|}{3090} & & \\
\hline
\end{tabular}

$\star \star \star, ~ * \star$, *; Significância a 1\%, 5\% e 10\%

De acordo com a Tabela 6, os resultados do teste de heterocedasticidade, correlação serial e multicolinearidade indicam que as hipóteses de homocedasticidade e de não correlação serial foram rejeitadas. Porém, a multicolinearidade apresentou valor de 1,66, que segundo Hair (2005), os valores entre 1 e 10 apresentam multicolinearidade aceitável.

Conforme o teste de Hausman (1978), fica averiguado que ele indica a análise por meio dos efeitos fixos, o qual é apresentado nas duas últimas colunas o modelo corrigido por meio da utilização da correção de Newey-West (1987).

Nos resultados da regressão não foi encontrada significância estatística entre AD e IFRS. No modelo apresentado é comprovado que apenas o endividamento (ENDIV) e o tamanho da empresa (TAM) possuem uma relação significativa estatisticamente com os accruals discricionários (AD). Para as demais variáveis, embora conste uma ligação entre elas na literatura, não foi possível comprovar a causalidade estatisticamente.

Com os resultados obtidos nos dois testes realizados, é possível afirmar que houve uma redução nos níveis de GR após 2010, ano em que houve a adoção completa de IFRS, mas não é possível afirmar que o evento da adoção de IFRS foi responsável por essa mudança. Assim, não é possível afirmar que a aderência à norma internacional reduziu ou aumentou o nível de GR nas empresas brasileiras de capital aberto de acordo com o modelo proposto.

O resultado obtido com a variável TAM se alinha aos embasamentos teóricos de que quanto maior a empresa menor o gerenciamento de seus resultados, conforme Gu, Lee e Rosett (2005) e Tendeloo e Vanstraelen (2005).

A relação entre AD e ENDIV também confirma os resultados dos trabalhos de Watts e Zimmerman (1990) e Defond e Jiambalvo (1994), que sugerem uma relação positiva com AD, ou seja, quanto maior a dívida maior o GR. É interessante notar que ENDIV é um fator presente que afeta significativamente AD em todo o período considerado no estudo, independentemente da adoção de IFRS, o que sugere que as empresas brasileiras, com alto grau de concentração acionária, mantêm maior preocupação em relação às informações prestadas às fontes de capital de terceiros. 


\section{Considerações Finais}

O estudo analisou o nível de gerenciamento de resultado no período de transição das normas contábeis brasileiras para o padrão internacional. $O$ trabalho tratou de dois assuntos relevantes para área de contabilidade e procura contribuir com a literatura na área de GR e IFRS, tendo em vista que estas áreas estão relacionadas com a qualidade da informação contábil das companhias.

Foi realizado um teste de hipótese de diferença de médias dos accruals discricionários (AD) antes e após 2010, ano em que houve a adoção completa das IFRS pelas companhias abertas brasileiras. Verificou-se que houve uma redução nos níveis de accruals discricionários entre os períodos analisados.

Porém, como é possível que essa redução não tenha ocorrido em função do evento de adoção de IFRS, realizou-se um teste de regressão com dados em painel para verificar se este evento foi capaz de explicar mudança nos $\mathrm{AD}$ no período analisado.

As análises dos dados realizadas em painel não mostraram uma influência da adoção de IFRS sobre os accruals discricionários. Esses resultados também foram obtidos na pesquisa de Elbannan (2011), que não encontrou uma relação significativa entre as duas variáveis.

Entretanto, obteve-se resultado de causalidade entre AD e a variável TAM, que confirmam os resultados de Gu, Lee e Rosett (2005) e de Tendeloo e Vanstraelen (2005).

Obteve-se também significância estatística na relação entre AD e ENDIV, confirmando os resultados dos trabalhos de Watts e Zimmerman (1990) e Defond e Jiambalvo (1994)

Esses resultados obtidos mostram que, apesar de ter havido redução nos níveis de AD após 2010, não é possível afirmar que isso tenha ocorrido em função do evento de adoção de IFRS. Os AD continuam sendo menores para empresas grandes e maiores para empresas endividadas, mesmo com a adoção de IFRS. No conjunto, os resultados sugerem que empresas maiores e com maior proporção de capital próprio tendem a produzir relatórios com melhor qualidade, o que remete à necessidade de crescimento do mercado acionário brasileiro.

Uma limitação do trabalho se deve ao fato de que a alteração recente restringe a amostra de dados. Outra limitação se deve ao fato de a nova norma gerar mudanças no resultado da empresa, pois existem novas formas de tratar os ativos financeiros, os biológicos, pois o valor justo altera a forma de avaliação dos ativos e consequentemente afeta todo o resultado da empresa. Mesmo com alterações em seus accruals, essas companhias não necessariamente estariam gerenciando seu resultado e sim demonstrando as implicações da nova norma nos lucros ou prejuízos.

Para futuras pesquisas é interessante verificar outros fatores que possam ter influenciado a redução nos níveis de AD após 2010, como a neutralidade tributária, a crise financeira de 2008, o período de adaptação às normas entre 2008 e 2009 etc. É interessante também estabelecer a relação entre adoção de IFRS e AD com um período maior de análise, pois neste primeiro momento existe a limitação dos dados no período em conformidade com as IFRS e eventuais interferências do período de transição. Sugere-se também para futuras pesquisas a utilização do modelo de Tendeloo e Vanstraelen (2005), que inserem uma variável dummy para empresas auditadas pelas big four. Uma outra sugestão é a mensuração do fenômeno, com o isolamento das demonstrações que foram afetadas pela crise financeira mundial de 2008. Analisar se as possíveis alterações no nível de GR foram causadas pela maior regulação da CVM, pelo aprimoramento em governança corporativa ou pelo regime tributário de transição também são propostas para novos estudos. Outra sugestão é alterar a forma de cálculo das variáveis de controle ou inserir mais variáveis para aumentar o poder preditivo do modelo. Além destas, podem ser elaborados trabalhos com diferentes modelos de mensuração de GR, tais como: Kang e Sivaramakrishanan (1995), Pae (2005) e Paulo (2007). Outras pesquisas poderiam analisar a possibilidade das empresas apresentarem lucros ao invés de prejuízos, verificar a constância de grandes prejuízos utilizando o método da regressão logística ou analisando a frequência, a exemplo dado pelos trabalhos de Burgstahler e Dichev (1997) e de Cardoso (2005). 


\section{Referências}

Almeida, J. E. F. (2010) Qualidade da informação contábil em ambientes competitivos. Tese (Doutorado em Ciências Contábeis) - Departamento de Contabilidade e Atuária, Faculdade de Economia, Administração e Contabilidade, Universidade de São Paulo, São Paulo.

Akerlof, G. A. (1970). The market for "lemons": quality uncertainty and the market mechanism. Quarterly Journal of Economics, 84(3), p. 488-500.

Barth, M. E., Landsman, W. R. \& Lang, M. H. (2008). International Accounting Standards and Accounting Quality. Journal of Accounting Research, 46(3), p. 467-498. doi: 10.1111/j.1475-679X.2008.00287.x

Burgstahler, D. \& Dichev, I. (1997). Earnings management to avoid earnings decreases and losses. Journal of Accounting and Economics, 24(1), p. 99-126.

Cameron, A. C., Trivedi, P. K. (2005). Microeconomics: methods and applications. New York: Cambridge University Press.

Campos, T. L. C. (2006). Estrutura da propriedade e desempenho econômico: uma avaliação empírica para as empresas de capital aberto no Brasil. Revista de Administração, 41(4), p. 369-380.

Cardoso, R. L. (2005). Regulação econômica e escolhas de práticas contábeis: evidências no mercado de saúde suplementar. São Paulo, 2005. 163 f. Tese (Doutorado em Ciências Contábeis) - Departamento de Contabilidade e Atuária, Faculdade de Economia, Administração e Contabilidade, Universidade de São Paulo, São Paulo.

Cardoso, R. L., Saraiva, E., Tenório, F. G. \& Silva, M. A. (2009). Regulação da contabilidade: teorias e análise da convergência dos padrões contábeis brasileiros aos IFRS. Revista de Administração Pública, 43(4), p. 773-799.

Coelho, A. C. D. \& Lopes, A. B. (2007). Avaliação da prática de gerenciamento de resultados na apuração do lucro por companhias abertas brasileiras conforme seu grau de alavancagem financeira. Revista de Administração Contemporânea, 11(Esp.2), p. 121-144.

Dechow P. M., Sloan, R. G. \& Sweeney, A. P. (1995). Detecting earnings management. The Accounting Review, 70(2), p. 193-225.

Dechow, P. M. \& Dichev, I. D. (2002). The quality of accruals and earnings: the role of accrual estimation errors. The Accounting Review, 77, 35-39.

Dechow, P. M., Ge, W. \& Schrand, C. (2010). Understanding earnings quality: A review of proxies, their determinants and their consequences. Journal of Accounting and Economics, 50(1-2), p. 344-401.

Defond, M. L. \& Jiambalvo, J. (1994). Debt covenant violation and manipulation of accruals. Journal of Accounting and Economics, 17(1-2), p. 145-176.

Defond, M. L. (2010). Earnings quality research: Advances, challenges and future research. Journal Accounting and Economics, 50(2-3), p. 402-409.

Dhaliwal, D. S. (1980). The effects of the firm's capital structure on the choice of accounting methods. The Accounting Review, 55(1), p. 78-84.

Easley, D. \& O'Hara, M. (2004). Information and the cost of capital. The Journal of Finance, 59(4), p. 1553-1583.

Elbannan, M. A. (2011). Accounting and stock market effects of international accounting standards adoption in an emerging economy. Review of Quantitative Finance and Accounting, 36(2), p. 207-245.

Fields, T. D., Lys, T. Z. \& Vincent, L. (2001). Empirical research on accounting choice. Journal of Accounting and Economics, (31), p. 255-307. 
Francis, J., Lafond, R., Olsson, P. \& Schipper, K. (2005). The market pricing of accruals quality. Journal of Accounting and Economics, (39), p. 295-327.

Goncharov, I., Zimmermann, J. (2006). Earnings management when incentives compete: the role of tax accounting in Russia. Journal of International Accounting Research, 5(1), 41-65.

Gu, Z., Lee, C. W, J. \& Rosett, J. G. (2005). What determines the variability of accounting accruals? Review of Quantitative Finance and Accounting, (24), p. 313-334.

Guay, W. R., Kothari, S. P. \& Watts, R. (1996). A market-based evaluation of discretionary accruals model. Journal of Accounting Research, 34(Supl.), p. 85-105.

Hair, J. F., Anderson, R. E., Tatham, R. L., Black, W. C. \& Babin, B. J. (2005). Análise multivariada de dados. 5. ed. Porto Alegre: Bookman.

Hausman, J. A. (1978). Specification tests in econometrics. Econometrica, 46(6), p. 1251-1271.

Healy, P. M. (1985). The effect of bonus schemes of accounting decisions. Journal of Accounting and Economics, (7), p. 85-107.

Healy, P. M. (1996). Discussion of a market-based evaluation of discretionary accrual models. Journal of Accounting Research, 34(Supl.), p. 107-115.

Iatridis, G. \& Rouvolis, S. (2010). The post-adoption effects of the implementation of International Reporting Standards in Greece. Journal of International Accounting, Auditing and Taxation, (19), p. 55-65.

Iatridis, G. (2010). International Financial Reporting Standards and the quality of financial statement information. International Review of Financial Analysis, 19(3), p. 193-204.

Iatridis, G. (2012). Audit quality in common-law and code-law emerging markets: evidence on earnings conservatism, agency costs and cost of equity. Emerging Markets Review, 13(2), p.101-117.

Jeanjean, T. \& Stolowy, H. (2008). Do accounting standards matter? An exploratory analysis of earnings management before and after IFRS adoption. Journal of Accounting Public Policy, (27), p. 480-494.

Jensen, M. \& Meckling, W. H. (1976). Theory of the firm: managerial behavior, agency costs and ownership structure. Journal of Financial Economics, 3(4), p. 305-360.

Jones, J. J. (1991). Earnings management during import relief investigations. Journal of Accounting Research, 29(2), p. 193-228.

Kang, S. H. \& Sivaramakrishnan, K. (1995). Issues in testing earnings management: an instrumental variable approach. Journal of Accounting Research, 33(2), p. 353-367.

Kohlbeck, M. \& Warrfield, T. (2010). Accounting standard attributes and accounting quality: Discussion and analysis. Research in Accounting Regulation, 22(2), p. 59-70.

Kothari, S. P. \& Leone, A. J., Wasley, C. E. (2005). Performance matched discretionary accrual measures. Journal of Accounting and Economics, 39(1), p. 163-197.

Land, J. \& Lang, M. (2002). Empirical evidence on the evolution of international earnings. The Accounting Review, 77(Supl.), p. 115-133.

Lei n. 11.638, de 28 de dezembro de 2007. (2007) Altera e revoga dispositivos da Lei n. 6.404, de 15 de dezembro de 1976, e da Lei n. 6.385, de 7 de dezembro de 1976, e estende às sociedades de grande porte disposições relativas à elaboração e divulgação de demonstrações financeiras. Diário Oficial da União, edição extra, Poder Executivo, Brasília, DF, 28 dez. 2007.

Lei n. 11.941, de 27 de Maio de 2009. (2009) Altera a legislação tributária federal relativa ao parcelamento ordinário de débitos tributários; concede remissão nos casos em que especifica; institui regime tributário de transição, alterando o Decreto no 70.235, de 6 de março de 1972; e dá outras providências. Diário Oficial da União, edição extra, Poder Executivo, Brasília, DF, 28 maio 2009. 
Lei n. 6.404, de 15 de dezembro de 1976. (1976) Dispõe sobre as Sociedades por Ações. Diário Oficial da União, Poder Executivo, Brasília, DF, 17 dez. 1976. Suplemento.

Leuz, C., Nanda, D. \& Wysocki, P. D. (2003). Earnings management and investor protection: an international comparison. Journal of financial economics, (69), p. 505-527.

Lopes, A. B. (2002). A informação contábil e o mercado de capitais. São Paulo: Pioneira Thomson Learning.

Martinez, A. L. (2001). Gerenciamento dos resultados contábeis: estudo empírico das companhias abertas brasileiras. Tese (Doutorado em Ciências Contábeis) - Departamento de Contabilidade e Atuária, Faculdade de Economia, Administração e Contabilidade, Universidade de São Paulo, São Paulo.

Martins, E., Martins, V. A. \& Martins, E. A. (2007). Normatização contábil: ensaio sobre sua evolução e o papel do CPC. Revista de Informação Contábil, 1(1), p. 7-30.

McNichols, M. \& Wilson, G. P. (1988). Evidence of Earnings management from the provision for bad debts. Journal of Accounting Research, 26(Supl.), p. 1-31.

Medida Provisória n. 449, de 3 de dezembro de 2008. (2008) Altera a legislação tributária federal relativa ao parcelamento ordinário de débitos tributários, concede remissão nos casos em que especifica, institui regime tributário de transição e dá outras providências. Diário Oficial da União, Poder Executivo, Brasília, DF, 4 dez. 2008.

Myers, J. N., Myers, L. A. \& Skinner, D. J. (2007). Earnings momentum and earnings management. Journal of Accounting, Auditing, and Finance, 22(2), p. 249-284.

Newey, W. K. \& West, K. D. (1987). A simple, positive semi-definite, heteroskedasticity and autocorrelation consistent covariance matrix. Econometrica, 55(3), p. 703-708.

Pae, J. (2005). Expected accrual model: the impact of operating cash flows and reversals of accruals. Review of Quantitative Finance and Accounting, (24), p. 5-22.

Paulo, E. (2007). Manipulação das informações contábeis: uma análise teórica e empírica sobre os modelos operacionais de detecção de gerenciamento de resultados. Tese (Doutorado em Contabilidade) - Departamento de Contabilidade e Atuária, Faculdade de Economia, Administração e Contabilidade, Universidade de São Paulo, São Paulo.

Subramanyam, K. R. (1996). The pricing of discretionary accruals. Journal of Accounting and Economics, 22(1-3), p. 249-281.

Sweeney, A. (1994). Debt-covenant violations and managers' accounting responses. Journal of Accounting and Economics, 17(3), p. 281-308.

Tendeloo, B. V. \& Vanstraelen, A. (2005). Earnings management under German GAAP versus IFRS. European Accounting Review, 14(1), p. 155-180.

Valle, M. R. (2007). A estrutura de capital das empresas brasileiras num ambiente de altas taxas de juros e na presença de fontes diferenciadas de financiamento. Tese (Livre-docência) - Departamento de Contabilidade, Faculdade de Economia, Administração e Contabilidade de Ribeirão Preto, Universidade de São Paulo.

Watts, R. \& Zimmerman, J. (1990). Positive accounting theory: a ten-year perspective. The Accounting Review, 65(1), p. 131-156.

Xiong, Y. (2006). Earnings management and its measurement: a theoretical perspective. The Journal of American Academy of Business, 9(2), p. 214-219. 